SPECIAL ARTICLE

\title{
HbA1c measurement in diabetes diagnosis and management of diabetes in latin: proceedings of the San Pablo Symposium
}

Juan José Gagliardino, on behalf of the San Pablo HbA1c Symposium

Professor, CENEXA, Centro de Endocrinología Experimental y Aplicada (UNLP-CONICET La Plata), School of Medicine, La Plata University, Argentina

\section{ABSTRACT}

This HbA1c Symposium, attended by expert clinicians and scientists from Latin America and Europe, aims to create a regional forum to discuss the current role of $\mathrm{HbA} 1 \mathrm{C}$ measurement in diagnosis and management of diabetes in the context of the current burden and state of care for diabetes in four Latin American countries. In view of difficulties arising from a lack of a standardized procedure for HbA1c measurement with the consequent negative impact on a suitable tool to evaluate glycemic control, clinical diabetes experts and representatives of the International Federation of Clinical Chemistry decided to work together to search for a long-term pragmatic solution. This shared commitment indicates that this Symposium could be the starting point of a permanent $\mathrm{HbA} 1 \mathrm{c}$ forum to find

\section{RESUMEN}

Este Simposio sobre la medición de la hemoglobina glucosilada (HbA1c), al que asistieron expertos clínicos y científicos de América Latina y Europa, tiene como objetivo crear un foro regional para analizar el papel actual de la medición de la $\mathrm{HbA} 1 \mathrm{c}$ en el diagnóstico y tratamiento de la diabetes en el contexto de la carga, así como la exposición del estado actual de la atención sanitaria a los pacientes diabéticos en cuatro países latinoamericanos. En vista de las dificultades derivadas de la falta de un procedimiento estandarizado para la medición de la $\mathrm{HbA} 1 \mathrm{c}$, con el consiguiente impacto negativo en una herramienta adecuada para evaluar el control glucémico, los expertos clínicos en diabetes y representantes de la Federación Internacional de Química Clínica decidieron trabajar jun- 
and monitor the implementation of a suitable standardization $\mathrm{HbA} 1 \mathrm{C}$ procedure to effectively benefit health systems, health care providers, supporting organizations, and especially people with diabetes in Latin America. (Rev ALAD. 2018;8:8-21)

Corresponding author: Juan José Gagliardino,

cenexaar@yahoo.com.ar

Keywords: HbA1c measurement. Diabetes diagnosis and control. HbA1c methods. Diabetes burden in Latin America. HbA1c standardization programme. tos para buscar una solución pragmática a largo plazo. Este compromiso compartido indica que este Simposio podría ser el punto de partida de un foro permanente sobre la HbA1c para encontrar y monitorizar la implementación de un procedimiento adecuado de estandarización de medición de la HbA1c que beneficie de manera efectiva a los sistemas de salud, proveedores de atención médica, organizaciones de apoyo y, especialmente, a las personas con diabetes en América Latina.

Palabras clave: Medición de la HbA1c . Diagnosis y control de diabetes. Carga de diabetes en Latinoamérica. Programa de estandarización de medición de la HbA1c.
The São Paulo HbA1c Symposium, held on October 21-22, 2016, was attended by an interdisciplinary and intersectional group of expert clinicians and scientists from Latin America and Europe. Its main objective was to create a regional forum to discuss the role of $\mathrm{HbA1C}$ measurement in diagnosis and management of diabetes in the context of the current burden and state of care for diabetes in four Latin American countries. Also to take advantadge of experience in this endeavor gained in some European countries. The latter included trends, technical and clinical aspects of diabetes care, and healthcare delivery and policy as presented by clinical experts. The former included the use of HbA1c in clinical practice, its quantification, standardization, quality control, and types of interference in its measurement, presented by scientific experts. This paper summarizes data presented in this Symposium. We hope this meeting and its conclusions will be the first step of a permanent cooperative initiative attempting to attain a standardized procedure for HbA1 measurement in the Region of Latin America in order to improve its capacity for the diagnosis and appropriate control of diabetes management.

\section{DIABETES BURDEN AND CARE IN LATIN AMERICA. GENERAL CONCEPTS}

Diabetes is a group of chronic metabolic diseases characterized by hyperglycemia resulting from defects in insulin secretion, insulin action, or their combination ${ }^{1}$. The chronic hyperglycemia of DM is associated with development of microvascular and macrovascular complications.

The International Diabetes Federation has declared a global diabetes epidemic: in 2015 more than 425 million people had diabetes mellitus (DM) 
worldwide, and it is expected to increase to 642 million by $2040^{2}$. Type 2 diabetes (T2D) accounts for over $90 \%$ of cases, type 1 diabetes (T1D) accounts for $5-10 \%$, and the remainder of cases are due to other aetiological causes. This global growth of DM is linked to epidemiological, demographic, and nutritional changes that arise in the context of economic growth, progressive urbanization, and increased life expectancy. These changes in lifestyle are contributing significantly to the rapid rise in obesity (decreased physical activity, increased intake of fat, sugar, and processed foods). Approximately half of the people with $T_{2} \mathrm{D}$ are unaware that they have this disease, its prevalence increasing with age and also being associated with low levels of education and income. All together, these changes result in a heavy burden not only on the health care system, the productive system and the overall society. In this sense, the diabetes burden represents the third largest risk factor overall for death and the eighth in relation to loss of disability-adjusted life years, mainly due to serious cardiovascular events ${ }^{3}$. Many studies support this concept and, for example, the INTERHEART study has shown that $12.9 \%$ of myocardial infarctions are attributable to diabetes in Latin America ${ }^{4}$. It is therefore urgent to establish a coordinated multi-sectorial, interdisciplinary approach to contain this rapidly growing and serious health problem.

To provide evidence of diabetes impact in Latin America, in this opportunity four countries in this region described their national burden and care.

\section{Colombia}

The prevalence of T2D in the adult population (over 20 years of age) is between 7 and $9 \%$, but is 5 times lower in the rural population. The resulting 2 million people with $T 2 D$ represent a challenge for the future, especially regarding the need to identify and treat those who undiagnosed 5 . The CARMELA study reported that a cohort of 1,553 people (average age 47.5 years) living in Bogotá (Colombia) had a prevalence of $\mathrm{T}_{2} \mathrm{D}$ of $8.1 \%$ (7.4\% in women and $8.7 \%$ in men) ${ }^{6}$.

In 2005, prevalence of self-reported diabetes diagnosis in adults (18 to 64 years of age) was $5.7 \%$, with higher prevalence in adults between 50 and 64 (11.9\%), in males $(7.5 \%)$, in those with no schooling (6.5\%), and in those with low incomes (9.0\%) (National Survey on the Nutritional Situation in Colombia-ENSIN) ${ }^{7}$. This is quite alarming, considering that no field screening test was performed. There is no reliable information on how rapidly the number of people with diabetes is increasing with the rapid increase in obesity, and we may expect it to increase in parallel with the degree of adiposity. Comparing data from the two ENSIN surveys (2005 and 2010) of people between 18 and 64 years of age, we see that the prevalence of overweight/obesity increased by $5.1 \%$, while that of overweight and obesity separately increased $2.3 \%$ and $2.8 \%$, respectively, over a 5 -year period ${ }^{8}$.

In Colombia, the national healthcare system has two large entities: the Subsidized and the Contributive system; the former includes low income patients whose healthcare plan is subsidized by the government; whereas the latter includes employees who had a $12.5 \%$ monthly deduction of their salaries for healthcare coverage (established by law), called POS based on its acronym in Spanish?.

In the case of DM, the POS includes services such as care of patients after the first consultation by an endocrinologist and other specialists (i.e. Ophthalmologists), and treatment with drugs such as metformin (except the extended-release form), glibenclamide, and all kinds of insulin, including analogs, 
and diabetes care supplies such as blood glucose meters, 100 test strips for people with T1D, insulin pens, needles or syringes, and also insulin pumps. Laboratory tests such as plasma glucose measurement is included for diagnosis (mandatory in adults over 40), oral glucose tolerance test and glycated hemoglobin (HbA1c). The POS does not include 24 hour continuous glucose monitoring, but it may be requested through the Technical-Scientific Committee.

Since T2D is one of the 5 leading causes of death and one of the 10 major causes of medical consultation in the adult population in Colombia, the Colombian Administrative Department of Science, Technology and Innovation (COLCIENCIAS) has requested the Health Technology Assessment Institute and the Pontificia Universidad Javeriana, to prepare a clinical practice guideline for diagnosis, treatment, and follow-up of T2D in the population over 18 years of age (guideline No. GCP-2015-51). Although this guideline was not published in a scientific journal, it has been available locally since March 2016. Its major initial objective was to identify undiagnosed diabetic people who could benefit from early diagnosis/treatment ${ }^{5}$.

This guideline considers criteria for screening and diagnosis of T2D with cut-off values similar to the ones proposed by the ADA one and in order avoid repetitions we provide the pertinent reference ${ }^{1}$.

The guideline also provides values to identify people at risk of developing diabetes, screened by the FINDRISC questionnaire ${ }^{10}$ followed by the oral glucose tolerance test (OGTT), namely: impaired fasting glucose (IFG) and impaired glucose tolerance (IGT). In all cases, education regarding the adoption of a healthy lifestyle is recommended, including an emphasis on the importance of good glycemic control to reduce microvascular complications.
The use of HbA1c is suggested as a strategy for diagnosis of T2D in patients with fasting plasma glucose levels between 100 and $125 \mathrm{mg} / \mathrm{dl}^{11}$. It could also be used to confirm the diagnosis when the results of fasting plasma glucose are discordant (i.e. when the two blood glucose measurements are discrepant: one is $>125$ and the other is <125). A HbA1c value $\geq 6.5 \%$ confirms diagnosis.

Warnings about $\mathrm{HbA} 1 \mathrm{C}$ measurements are included in the guideline:

- The centers that perform HbA1c test must comply with international guidelines, ensuring that the available kits in the country as well as the methods used are certified by the National Glycohemoglobin Standardization Program $(\mathrm{NGSP})^{12}$.

- If clinical suspicion of T2D is high and the HbA1C value is below $6.5 \%$, an OGTT should be performed to confirm diagnosis or to establish the presence of categories indicating a greater risk of diabetes (prediabetes).

\section{Brazil}

Has a total population of 206 million inhabitants with a life expectancy of 74.8 years ${ }^{13}$. Diabetes prevalence is $8.68 \%$ (equivalent to 11.6 million people with diabetes); with this figure Brazil is the $4^{\text {th }}$ nation in terms of number of people with diabetes in the world, just after China, India and the USA ${ }^{14,15}$.

The cost of diabetes care for these people is about USD 1,527/year per person. Diabetes is also responsible for 116,382 deaths/year ${ }^{16-18}$. The average HbA1c value is $9.1 \%$ and only $11.6 \%$ of people with diabetes achieve recommended glycemic target values ${ }^{19}$. 
People in Brazil with T2D dislike insulin therapy, mainly because it represents:

- a rigid schedule,

- inconvenient time and frequency of administration,

- pain and body injuries associated with injections,

- inconvenience in public places,

- fear of injections,

- feelings that disease had progressed,

- weight gain,

- higher frequency of hypoglycemia.

Although, they prefer a more effective, non-injectable treatment with fewer side-effects, they are not willing to pay out-of-pocket for these advantages. They were also particularly concerned about the risk of hypoglycemia, expressed a strong desire to avoid injections, and complained that health providers paid little attention to their problems.

The Brazilian Society of Diabetes developed its own diabetes control and treatment clinical practice guidelines and the Public Health System provides free drugs for hyperglycemia (metformin in all its presentations, glyburide, gliclazide, human insulinnot analogues), as well as for anti-hypertensive medications ${ }^{20}$. The private system covers all dipeptidyl peptidase-4 (DPP4- inhibitors) and sodium glucose cotransporter 2 inhibitors (SGLT2-inhibitors), pioglitazone, human insulin and analogues.

Concerns and warnings about $\mathrm{HbA1c}$ measurement in Brazil will be described in other section of this report.
In summary, Brazil is a complex country with large T1D and T2D populations, often poorly controlled despite they have reasonable access to care and treatment.

\section{Mexico}

Mexico is among the main consumers of sweetened soft drinks and one of the countries with the bigggest number of obese individuals. Combined prevalence of obesity and overweight in adults is $71.3 \% 21,22$.

Diagnosed diabetes prevalence is 9.2\%, which means that 12 million adults 20 and older have diabetes, which is also the main cause of death in adults 5574; healthcare expenditures required for their care represents $2.4 \%$ of the Gross Domestic Product ${ }^{23,24}$.

Only $9.6 \%$ of patients with diabetes are monitored with $\mathrm{HbA} 1 \mathrm{C}$ while $25 \%$ of them attained values $\leq 7 \%$. In 2008, the Staged Diabetes Management Program «MIDE» implemented at the Instituto de Seguridad y Servicios Sociales de los Trabajadores del Estado (ISSSTE) changed the paradigm of diabetes care in Mexico: it was the first institution to use HbA1c as the glycemic monitoring test, setting the tone to revolutionize diabetes care in the country ${ }^{25}$. The MIDE Program was launched in 2014 and has contributed to the integration of the National Strategy for Prevention and Control of people with overweight/obesity and diabetes. In MIDE currently $100 \%$ of patients are monitored with $\mathrm{HbA} 1 \mathrm{C}$, and $62 \%$ achieved treatment target values.

In 2016, the Official Mexican Standard (NOM 015 SSA in Spanish) for the prevention, diagnosis, detection, treatment, and control of diabetes included $\mathrm{HbA} 1 \mathrm{c}$ as a glycemic monitoring method (at least two per year $)^{26}$. Currently, HbA1c monitoring is a public policy in Mexico. 


\section{Argentina}

Diabetes prevalence in Argentina rose from 8.4 to 9.8\% in the 2005-2013 period, being higher in the elderly, women with obesity and people with lower incomes and low educational levels ${ }^{27}$. The number of undiagnosed and untreated people is high and, despite the available evidence that good control of glycemic and associated cardiovascular risk factors can delay the onset/progression of microvascular and macrovascular complications, most people with diabetes do not achieve treatment goals to reach this prevention ${ }^{28}$. This condition results in decreased quality of life of these people and increased cost of care. For example, diabetic retinopathy is the first cause of non traumatic blindness while diabetic nephropathy is the leading cause of patients in dialysis, accounting for $34.7 \%$ of incidental cases and $22.8 \%$ of renal failure ${ }^{29,30}$. However, the leading cause of death in people with diabetes is cardiovascular disease.

Prevalence of diabetes in Argentina, compared to other countries in the region, is higher than in Uruguay and in many Brazilian cities (between 3.6 and 6.9\%). The figures in Argentina are similar to those reported in the United States in 2009. A multicenter study published by Dr. Villariño et al. in 2014 showed considerably increased prevalence of T2D (from 7.9 to $10.8 \%$ overall in both genders) and obesity (from 26 to $33 \%$ ) in the central area of Argentina ${ }^{31}$.

Not all people with diabetes have yearly control of $\mathrm{HbA1c}$ and not all the laboratories in the country use for its measurement methods certified by the National Glycohemoglobin Standardization Program $(\mathrm{NGSP})^{13}$.

Gagliardino et al. have shown that education of healthcare providers and people with diabetes can effectively change this situation, but in order to achieve a real change, it might be necessary to implement these programs at the primary care level and to establish coordinated activity between the different levels of care. To achieve this aim the same group has implemented several programs, such as PROPAT developed by IOMA (in Spanish, Instituto de Obra Médica Asistencial, a social security organization in the Province of Buenos Aires) ${ }^{32}$, the PRODIACOR program in the Province of Corrientes 33 and, most recently, DIAPREM in the Municipality of La Matanza, Buenos Aires Province ${ }^{34}$. In all these programs, education given and organization of care promoted a significant improvement in clinical and metabolic indicators and also reduced care costs. In the third program, it was added systematic record-keeping of clinical, metabolic and therapeutic indicators (QUALIDIAB) ${ }^{35}$, the set-up of a call center, and yearly scheduled consultation with a cardiologist and an ophthalmologist. These interventions were implemented in 15 primary care centers (CAP, centros de atención primaria) of this municipality, where an education program was implemented for primary care physicians and nurses who see 150 patients with T2D using an organized educated team approach (Physicians and Nurses). Their results were compared to those obtained at another 15 CAPs by physicians and nurses carrying out their care activities in the usual manner. Although that program startup, patients in both groups showed indicators of similarly poor quality of care (low percentage of patients with values for BMI, HbA1c, blood pressure and target lipid profile); these indicators improved significantly after 6 months in the intervention group, and continued to improve after 12 months of follow-up. Conversely, no significant improvement in any of these parameters was recorded in the control group. Also, dropout in the intervention group decreased significantly (from 48 to $28 \%$ ). These results demonstrate that diabetes education implemented at all levels can improve the quality of care and the quality of life of people with diabetes, and also reduce the cost of their care ${ }^{32,33,36}$. 


\section{ROLE OF HbA1C IN DIABETES MANAGEMENT GUIDELINES}

Glycated hemoglobin (HbA1c) is a laboratory tool used to monitor glycemic control in diabetes patients for the last 30 years. It is formed by a spontaneous non-enzymatic reaction in which glucose binds covalently at $\mathrm{N}$-terminal valines of the $\mathrm{Hb}$ beta chain (glycation) ${ }^{37}$. The resultant glycated hemoglobin remains in red blood cells for the rest of its lifespan (3 months), and therefore its measurement gives a good parameter of glucose exposure to the body during this time-period. This method is now routinely used to assess glycemic control in the large majority of health care settings ${ }^{38}$. All major clinical trials including diabetes control and complications trials (DCCT) in T1D and the UKPDS in T2D have used it as a tool to monitor glycemic control39,40. Alltogether, they have demonstrated the benefits of intensive treatment in reference to the development/ progression of micro and macrovascular complications. The last 30 years' measurements of HbA1C have provided a piece of important evidence: elevated $\mathrm{HbA} 1 \mathrm{C}$ in a person without diabetes diagnosis shows a risk factor for cardiovascular disease ${ }^{41}$.

In the United Sates, where measurement methodology is standardized, HbA1c over $6.5 \%$ is a diagnostic value for diabetes ${ }^{42}$. As the occurrence of hypoglycemic events is closely related to lower HbA1c levels, most clinical societies have adopted an individualized target. For younger patients with longer life expectancy, without chronic complications, and using drugs with low risk for hypoglycemia, we should target strict control (lower levels of HbA1c). Conversely, for older patients, with high risk of hypoglycemia, or using insulin, suffering terminal diseases or with chronic kidney complications, the treatment target can be higher. Therefore, our current objective is to obtain good glycemic control and avoid hypoglycemia.
Factors others than diabetes can affect HbA1c levels: diseases that affect blood cell turnover such as hemolytic anemia and bleeding reduce the half-life of red blood cells, thus resulting in falsely low HbA1c values, whereas iron deficiency anemia that increases the half-life of red blood cells may result in falsely high HbA1c values ${ }^{43}$.

On the other hand, depending on the methodology applied, other medical conditions may interfere with HbA1c measurements, such as hypertriglyceridemia, hyperbilirubinemia, uremia, chronic alcoholism, and chronic use of opiates or salicylates. The presence of hemoglobin variants must be considered, particularly when the $\mathrm{HbA} 1 \mathrm{c}$ result does not correlate with the patient's blood glucose levels.

Current routine laboratory methods for determination of HbA1c levels include immunoassay, ion-exchange high performance liquid chromatography (HPLC), boronate affinity chromatography, enzymatic method, and capillary electrophoresis ${ }^{44}$. The use of a DCCT traceable method is recommended, certified by the National Glycohemoglobin Standardization Program (NGSP)45. Of the currently available methodologies, the immunoassay method has been highlighted due to its high accuracy and precision; it is also fully automated and certified by the NGSP46.

\section{STANDARDIZATION OF HbA1C MEASUREMENT: A LONG AND WINDING ROAD TO REACH THIS GOAL}

When the American Diabetes Association (ADA) began to recommend specific $\mathrm{HbA} 1 \mathrm{c}$ target treatment levels in 1994, the lack of comparability of HbA1C results among methods and laboratories made it 
difficult for healthcare providers to utilize these targets in clinical practice. Therefore, the NGSP was given in 1996 the task of harmonizing HbA1c results. The NGSP consists of a steering committee to oversee the program, an administrative core, and a network of reference laboratories that assist and certify manufacturers and clinical laboratories to harmonize $\mathrm{HbA} 1 \mathrm{c}$ results with those of clinical studies that established the link between HbA1c and outcome risks. The NGSP also maintains traceability to the laboratory network of the International Federation of Clinical Chemistry (IFCC) reference system for HbA1c.

Results from the College of American Pathologists whole blood survey are used to assess the effectiveness of the NGSP. The results have shown dramatic improvement in the comparability of $\mathrm{HbA} 1 \mathrm{c}$ results since 1994. However, although the NGSP was the groundbreaker for harmonization of HbA1c, further improvement is still needed, especially given recommendations (by ADA and the World Health Organization [WHO]) to use $\mathrm{HbA} 1 \mathrm{c}$ for the diagnosis of diabetes.

At that time, the lack of international standardization resulted in the development in several countries of national program which achieved harmonization of test results. However, in 2004, the International Federation of Clinical Chemistry and Laboratory Medicine (IFCC) Working Group on HbA1c Standardization, established a reference measurement procedure (RMP) for $\mathrm{HbA1c}$, embracing the concept of methodological traceability ${ }^{47}$.

After the development of the IFCC-RMP, the major organizations associated with diabetes care joined to construct a consensus statement highlighting that all HbA1c test results should be standardized worldwide, and that the new IFCC reference system represents the only valid anchor to implement standardization of the measurement. The consensus statement also highlighted that $\mathrm{HbA} 1 \mathrm{C}$ results should be reported in SI units with \% (DCCT) values in brackets, derived from the master equation.

More recently, the WHO advocated the use of $\mathrm{HbA1c}$ for diagnosis of diabetes, widening the role of testing ${ }^{48}$. Again, the use of results standardized to the international reference values was mandated. $\mathrm{HbA}_{1 \mathrm{c}}$ is widely used, since accurate and precise measurements are essential for patients care. Consistent, high-quality $\mathrm{HbA} 1 \mathrm{c}$ test results are imperative for clinicians and patients to make informed decisions about changes in therapy, and the IFCC-RMP is recognized as the anchor to be used to achieve this. Where targets are set on a global level, such as a value of $48 \mathrm{mmol} / \mathrm{mol}$ (6.5\%) HbA1c for the diagnosis of $T_{2} D$, it is paramount that true values are provided by routine laboratories. Deviations, due to bias or imprecision, can mean the difference that millions of people are potentially misdiagnosed when viewed on a global scale.

On a more individual level, patients whose glycemic control is monitored by $\mathrm{HbA1c}$ want reassurance that any changes in their $\mathrm{HbA} 1 \mathrm{c}$ are true, giving them and their clinicians confidence to adjust their therapy appropriately 49 .

\section{Two models of quality targets for HbA1c: Sigma metrics and biological variation}

The starting point for quality targets of an analyte in the medical laboratory is a reference method. This was well recognized by the IFCC, and a working group developed a reference method which is now well in place: this method has been officially 
approved, implemented in a worldwide network of reference laboratories, and used by manufacturers to target their kit calibrators and by organizers of external quality assessment programs to assign values to samples in their External Quality Assurance (EQA)/Proficiency Testing (PT) program ${ }^{50}$.

As a result of this analytical effort, from 1993 to 2014 the assay inter-laboratory coefficient of variation (CV) dropped from 22 to 3.5\%; this improvement enabled and caused a change in paradigm: the quality is currently so high that, rather than fasting plasma glucose, $\mathrm{HbA} 1 \mathrm{C}$ is being increasingly considered the gold standard for diagnosis and screening of diabetes.

This new application requires accurate and precise HbA1C assays. To address this question, the IFCC Task Force on HbA1c investigated two generic models: the Biological Variation and the Sigma Metrics model ${ }^{51}$. These models may be applied at the levels of: a) the individual laboratory (within one lab, within one method); b) the manufacturer (between laboratories, within one method) and; c) a country (between laboratories, between methods). With the aim of reaching international consensus for advice on quality targets for $\mathrm{HbA1c}$, the Task Force suggests the sigma-metrics model as the model of choice. The default goals in the model are the starting point for discussion with stakeholders in the field of diabetes and a drive towards improved quality.

Application of this model in several European countries and in the US demonstrated the current general status of HbA1c assays and whether they meet the quality targets set by the IFCC Task Force ${ }^{52}$. The general picture allows comparison of the performance of various analytical principles and commercial versions ${ }^{53}$. The Region of Latin America needs to attain such a tight control and agreement and hopefully this meeting will accelerate the process ti get it.

\section{Benefits of HbA1c standardization in daily practice}

The NGSP was established in 1996 for the purpose of standardizing $\mathrm{HbA} 1 \mathrm{C}$ test results to those of DCCT. The NGSP interacts with manufacturers to help them calibrate their methods and trace values to the $\mathrm{DCCT}^{53}$.

This calibration effort has improved harmonization of results among laboratories and has reduced imprecision. The use of a method certified by NGSP provides results comparable to those recorded in the DCCT study. Clinical laboratories should use HbA1C assays certified by NGSP and also participate in a proficiency testing program for HbA1c.

The NGSP offers three types of certification as follows 54 :

- Manufacturer method certification.

- Level I Laboratory Certification.

- Level II Laboratory Certification.

The NGSP recommends that manufacturers certify their methods every year. During that period, the manufacturer is responsible for ensuring that the results of their method remain consistent throughout the year and among different lots.

The IFCC established the IFCC Working Group (IFCC WG) on HbA1c standardization in 1995 and adopted a different approach. The IFCC WG developed a mixture of purified $\mathrm{HbA} 1 \mathrm{C}$ and $\mathrm{HbAo}$ as primary reference material and proposed two candidate reference 
methods: electrospray ionization mass spectrometry and capillary electrophoresis. The IFCC method reports $\mathrm{HbA} 1 \mathrm{c}$ as mmol/mol (HbA1c/total $\mathrm{Hb})^{51}$.

The list of current approved laboratories of the IFCC Network for HbA1c can be found at http://www.ifcchba1c.net/. There is a relation between the results of NGSP standardization (\%) and the IFCC network standardization $(\mathrm{mmol} / \mathrm{mol}){ }^{55}$. For its expression a master equation was developed as follows: $\mathrm{NGSP}=[0.09148 *$ IFCC $]+2.152$.

\section{Interferences in $\mathrm{HbA} 1 \mathrm{c}$ measurement by $\mathrm{Hb}$ Variants}

Although $\mathrm{HbA} 1 \mathrm{c}$ is routinely used to monitor longterm glycemic control and for diagnosing diabetes, the presence of hemoglobin $(\mathrm{Hb})$ genetic variants and $\mathrm{Hb}$ modifications may affect the accuracy of some methods.

It has been estimated that approximately $7 \%$ of the world population is a heterozygous carrier of some variant ${ }^{56}$. Therefore, based on the 2011 worldwide estimation of 366 million people with diabetes, around 26 million would have an $\mathrm{Hb}$ disorder, expected to double by $2030^{57}$.

Therefore, a variant $\mathrm{Hb}$ fraction may be an incidental finding during $\mathrm{HbA} 1 \mathrm{C}$ analysis, and $\mathrm{Hb}$ variants may interfere in different $\mathrm{HbA1C}$ measuring methods: high-performance liquid chromatography (HPLC), Boronate Affinity Chromatography and Immunoassays. Consequently, the NGSP advises laboratories to consider the likely prevalence of specific hemoglobinopathies in their population when selecting an $\mathrm{HbA} 1 \mathrm{C}$ assay ${ }^{54}$.

Data from the Hospital Universitario de Gran Canaria Doctor Negrin (Canary Islands, Spain) on HbA1C results obtained by the HPLC method (ADAMS ${ }^{\text {TM }}$ HA-8160 HPLC method [A Menarini Diagnostics, Florence, Italy]) showed that abnormal HPLC chromatograms were obtained for $163 / 42,371$ (0.38\%) samples. In 26 samples HbS was identified, and $\mathrm{HbA1C}$ results correlated with fasting plasma glucose and with the immunoturbidimetric assay Tina-quant ${ }^{\circledR}$ HbA1c Gen.3 assays (Roche Diagnostics, Mannheim, Germany) on the Cobas ${ }^{\circledR} 6000$ analyzer. In the remaining 137 samples $\mathrm{HbD}, \mathrm{Hb}$ Louisville, $\mathrm{Hb}$ Las Palmas, $\mathrm{Hb} \mathrm{N}$-Baltimore or $\mathrm{Hb}$ Porto Alegre were identified, and $\mathrm{HbA} 1 \mathrm{C}$ by the HPLC method did not correlate with FPG. These samples were retested by the immunoturbidimetric assay and the majority of results were accurate; only three (with the unstable $\mathrm{Hb}$ Louisville trait) gave aberrant $\mathrm{HbA} 1 \mathrm{C}$ results $5^{5}$. These data demonstrate that laboratories should be aware of $\mathrm{Hb}$ variants occurring locally and choose an appropriate $\mathrm{HbA} 1 \mathrm{c}$ testing method.

\section{Experience on new high-throughput- dedicated HbA1c analyzer}

Vall d'Hebron University Hospital (HUVH) Clinical Laboratories is the largest public clinical laboratory in Spain with a daily activity of 6,000 patient requests, over 16 million tests performed per year and an extensive test catalogue characterized by specialization. In this setting, over $800 \mathrm{HbA1c}$ determinations are performed daily in the laboratory.

From April to July 2015, HUVH Clinical Laboratories participated in the non-interventional, multicenter study to evaluate the reliability and analytical performance of the HbA1c Cobas C513 analyzer. System functionality, user interaction and analytical performance of this new analyzer were evaluated by the Tina-quant ${ }^{\circledR}$ HbA1c Gen 3 immunoassay (standardized to the approved IFCC reference method). Method comparisons were performed with a 
Menarini HA-8180V HPLC (the routine analyzer in the laboratory at that time) and with a dedicated HbA1C analyzer COBAS INTEGRA ${ }^{\circledR} 800$, using fresh and frozen anonymized residual routine samples.

The repeatability and intermediate precision of $\mathrm{HbA} 1 \mathrm{C}$ was $0.3-0.6 \%$ and $0.7-1.2 \%$, respectively, using both quality control materials and different sample pools. Recovery rates of 98.3 to $102.4 \%$ were obtained with IFCC reference materials. The comparison between Cobas $\mathrm{C} 513$ and Menarini HA-8180V was: $y=1.01$ (0.99, 1.02), $x+0.012(0.080,0.093)(n$ = 150); and the comparison with Cobas INTEGRA ${ }^{\circledR}$ 800 was; $y=1.00(1.00,1.01), x-0.15(-0.13,-0.18)$ $(n=10,052)^{59,60}$.

The evaluation study also demonstrated linearity in the range of $4.8-14.0 \%$ and no influence on the results by the common hemoglobin variants $\mathrm{HbAS}$, $\mathrm{HbAC}, \mathrm{HbAD}, \mathrm{HbAE}$ or the presence of HbA2. A later study carried out in this laboratory also concluded that $\mathrm{HbF}$ concentrations $<10 \%$ did not produce a significant interference in $\mathrm{HbA1c}$ results in Cobas $\mathrm{C} 513^{62}$. NGSP criterion establishes significant difference at $>7 \%{ }^{60} \mathrm{HUVH}$ Clinical Laboratories made a transition from three Menarini HA-8180V analyzers (40 samples/h) to a single Cobas c513 analyzer in February 2016 (400 samples/h). The workflow in the laboratory changed dramatically, eliminating the bottleneck caused by the HbA1c HPLC systems, and considerably reducing the time dedicated to analyzer maintenance tasks, sample handling, and technical validation. The analytical performance of the analyzer in this routine setting is also remarkable, with a CV\% for HbA1C QC concentrations $\approx 5 \%$ and $\approx 10 \%$ of $1.23 \%$ and $1.44 \%$, respectively, and $\mathrm{TE}<2 \%$.

The superior analytical performance of the HPLC systems has been contrasted with the immunoassay systems, and although it is true that the EQC panels support this affirmation, this difference has become smaller over the years, since the results obtained in the validation and routine performance of $c 513$ show that this system fulfills our laboratory quality specifications for $\mathrm{HbA} 1 \mathrm{c}$ analysis ( $\mathrm{CV}<1.5 \%$; $\mathrm{TE}<3 \%)$, with the added value of dramatically improving the workflow ${ }^{61}$.

\section{Closing remarks}

This interdisciplinary and intersectorial symposium represented simultaneously a great challenge and also an opportunity to identify effective strategies to cope with the ever- increasing burden of diabetes. The clinical experts have clearly described the seriousness and magnitude of the diabetes problem in the Latin American Region. The experts in clinical laboratory have presented evidence that in the Region standardized measurement of $\mathrm{HbA} 1 \mathrm{C}$ is far fom being a reality, thus, stressing the urgent need to implement an encompassing Latin American standardization programme to guarantee the provision of confident $\mathrm{HbA1c}$ results for diagnosis and follow up of people with diabetes. Different alternatives for reaching this objective were discussed and deeply analyzed, accompanied by examples of how to accomplish it. The discussion following each presentation gave the audience a good opportunity for an active exchange of ideas and opinions on the way the problem was solved in other regions or countries. These could be the basis for the development and implementation of a Regional Standardization programme with an active and effective international cooperation.

Since the President of the Latin American Association of Diabetes (ALAD) attended this meeting, we obtained his commitment to relay these messages and discuss them later with other members of ALAD to involve them in the search for dynamic solutions to achieve general standardization of $\mathrm{HbA} 1 \mathrm{c}$ measurement in this Region. Also, IFCC representatives 
have promised their support for the development of an education programme devoted to health-care team members on the importance of this issue. Altogether could successfully accomplish such attempt.

In view of this shared compromise, we hope that this meeting will be a starting point for an ongoing $\mathrm{HbA1c}$ forum to monitor this initiative, which will result in benefits for health systems, health care providers, supporting organizations and, above all, for people with diabetes.

\section{ACKNOWLEDGEMENTS}

We appreciate the support of Roche in holding this meeting. Roche did not participate in the content of the lectures or in the writing of this article.

Members of the San Pablo HbA1c meeting: Dr. Henar Balbuena (Vall d'Hebron University Hospital, Barcelona, Spain), Jorge Castillo Barcias (Colombian Society of Sarcopenia, Bogotá, Colombia), Antonio Roberto Chacra (Diabetes Center of the Federal University of Sao Paulo, Brazil), Alejandro Dain (del Prado Clinic, Cordoba, Argentina), Emma English (University of East Anglia, Norwick, UK), Félix Manuel Escaño Polanco (Presidente de la Alad en el momento del Simposio, República Dominicana), María Mercedes Lorenzo Medina (Dr. Negrin University Hospital, Gran Canaria, Spain), João Eduardo Nunes Salles (Faculty of Medical Sciences of the Santa Casa de Sao Paulo, Sao Paulo, Brazil), lyari Sánchez Díaz (Rehabilitation Basic Unit, Mexico, D.F. Government in Tlalpan), Nairo Massakazu Sumita (Fleury Medicine and Health, Sao Paulo, Brazil), Marcos Tambascia (University of Campinas, Campinas, Brazil), Milena Teles (Fleury Medicine and Health, Sao Paulo, Brazil) and Cas Weikamp (MCA laboratory of the Queen Beatrix Hospital, Winterswijk, The Netherlands).

\section{REFERENCES}

1. ADA Standards of Medical Care in Diabetes-2017. Diabetes Care 2017; 40 (Suppl1):S1-S135.

2. IDF Diabetes Atlas Group. Update of mortality attributable to diabetes for the IDF Diabetes Atlas: Estimates for the year 2013. Diabetes Res Clin Pract. 2015;109:461-5.

3. Global health risks: mortality and burden of disease attributable to selected major risks. World Health Organization. ISBN 978924 1563871 World Health Organization 2009.

4. Lanas F, Avezum A, Bautista LE, Diaz R, Luna M, Islam S and Yusuf S. INTERHEART Investigators in Latin America. Risk factors for acute myocardial infarction in Latin America: the INTERHEART Latin American study. Circulation 2007;115:1067-74.

5. Vargas-Uricoechea H, Casas-Figueroa LÁ. An Epidemiologic Analysis of Diabetes in Colombia. Ann Glob Health. 2015;81(6):742-53.

6. Schargrodsky $\mathrm{H}$, Hernández-Hernández R, Champagne BM, Silva $\mathrm{H}$, Vinueza R, Silva Ayçaguer LC, Touboul PJ, Boissonnet CP, Escobedo J, Pellegrini F, Macchia A, Wilson E; CARMELA Study Investigators. CARMELA: assessment of cardiovascular risk in seven Latin American cities. Am J Med. 2008;121(1):58-65.

7. Instituto Colombiano de Bienestar Familiar. Encuesta Nacional de la Situación Nutricional en Colombia, 2005. Bogotá, Panamericana Formas e Impresos, S.A.; 2006.

8. Herrán OF, Patiño GA, DelCastillo SE. Desigualdad y nutrición: Encuesta de la Situación Nutricional en Colombia, 2010. Rev Bras Saude Mater Infant. 2015, 15 (4):401-12.

9. https://www.minsalud.gov.co/salud/POS/Paginas/plan-obligatorio-de-salud-pos.aspx

10. Lindström J Tuomilehto J. The diabetes risk score: a practical tool to predict type 2 diabetes risk. Diabetes Care 2003; 26:725-31.

11. International Expert Committee Report on the Role of the A1C Assay in the Diagnosis of Diabetes. Diabetes Care 2009; 32:1327-34.

12. World Health Organization-Diabetes country profiles, 2016. Available at www.who.int/diabetes/country-profiles/bra_en.pdf?ua=1

13. Telo GH, Vogt Cureau F, de Souza MS, Andrade TS, Copês F and Schaan BD. Prevalence of diabetes in Brazil over time: a systematic review with meta-analysis. Diabetol Metab Syndr. 2016; 8(1):65.

14. Iser BP, Vigo Á, Duncan BB, Schmidt MI. Trends in the prevalence of self-reported diabetes in Brazilian capital cities and the Federal District, 2006-2014. Diabetol Metab Syndr. 2016; 13;8:70.

15. Bahia LR, Araujo DV, Schaan BD, Dib SA, Negrato CA, Leão MPS, Ramos AJS, Forti AC, Gomes MB, Foss MC, Monteiro RA, Sartorelli D, Franco $L$ : The costs of type 2 diabetes mellitus outpatient care in the Brazilian public health system. Value Health. 2011;14 (5 Suppl 1): S137-S40.

16. Botelho Borges N, Bosi Ferraz M and Chacra AR. The cost of type 2 diabetes in Brazil: evaluation of a diabetes care center in the city of São Paulo, Brazil. Diabetol Metab Syndr. 2014;6:122.

17. Schmidt MI, Duncan BB, Ishitani L, da Conceição Franco G, de Abreu DM, Lana GC, França E. Trends in mortality due to diabetes in Brazil, 1996-2011. Diabetol Metab Syndr. 2015; 26;7:109.

18. Baptista DR, Thieme RD, Reis WC, Pontarolo R, Correr CJ. Proportion of Brazilian diabetes patients that achieve treatment goals: implications for better quality of care. Diabetol Metab Syndr. 2015;14;7:113.

19. Lerario AC, Chacra AR, Pimazoni-Netto A, Malerbi D, Gross JL, Oliveira JEP, Gomes MB, Santos RD, Fonseca RMD, Betti R and Raduan R. Algorithm for the treatment of type 2 diabetes: a position statement of Brazilian Diabetes Society. Diabetol Metab Syndr. 2015;14;7:113.

20. Rivera JA, Barquera S, González-Cossıo T, Olaiz G and Sepúlveda J.Nutrition Transition in Mexico and in Other Latin American Countries. Nutrition Reviews 2004;62:S149-S57. 
21. Barquera S, Campos-Nonato Ismael, Hernández-Barrera L, Pedroza-Tobías Andrea, Rivera-Dommarco JA. Prevalencia de obesidad en adultos mexicanos, ENSANUT 2012, Vol. 55. Cuernavaca, Mexico: Salud Pública de México. 2013. suplemento 2.

22. Meza R, Barrientos-Gutierrez T, Rojas-Martinez R, Reynoso-Noverón N, Palacio-Mejia LS, Lazcano-Ponce E, Hernández-Ávila M. Burden of type 2 diabetes in Mexico: past, current and future prevalence and incidence rates. Prev Med. 2015;81:445-50.

23. Salas-Zapata L, Palacio-Mejía LS, Aracena-Genao B, Hernández-Ávila JE, Nieto-López ES. Costos directos de las hospitalizaciones por diabetes mellitus en el Instituto Mexicano del Seguro Social. Gac Sanit. 2016 Aug 2. pii: S0213-9111(16)30139-X. doi: 10.1016/j.gaceta. 2016.06.015. [Epub ahead of print]

24. http://www.sgm.issste.gob.mx/medica/diabetes/doctos/Lineamientos\%202014.pdf

25. http://www.salud.gob.mx/unidades/cdi/nom/m015ssa24.html)

26. Tercera Encuesta Nacional de factores de riesgo para enfermedades no transmisibles. 1.a Buenos Aires: Ministerio de Salud de la Nación, Instituto Nacional de Estadísticas y Censos, 2015 [consultado 25 Oct 2016]. Disponible en: http://www.msal.gov.ar/ent

27. Commendatore V, Dieuzeide G, Faingold C, Fuente G, Luján D, Aschner P, Lapertosa S, Villena Chávez J, Elgart J, Gagliardino JJ; DIFAR Academic Committee. Registry of people with diabetes in three Latin American countries: a suitable approach to evaluate the quality of health care provided to people with type 2 diabetes. Int J Clin Pract. 2013;67:1261-6.

28. Gonzalez L, Caporale JE, Elgart JF, Gagliardino JJ. The burden of diabetes in Argentina. Glob J Health Sci. 2014 Nov 17;7(3):124-33.

29. Elgart JF, Asteazarán S, De La Fuente JL, Camillucci C, Brown JB, Gagliardino JJ. Direct and indirect costs associated to type 2 diabetes and its complications measured in a social security institution of Argentina. Int J Public Health 2014; 59(5):851-7.

30. Vilariño JO, González CD, Grancelli H, Damiano M, Frechtel G, Costa Gil J, Ranalli C, Fox A, Tesone C and Sereday M. Aumento de la prevalencia de diabetes tipo 2 y obesidad en la zona central de Argentina (1997-2010): Un estudio multietápico sistemático demográfico. Estudio Venado Tuerto 2 (VT 2). Rev. ALAD 2014;4:140-7.

31. Gagliardino JJ, Olivera E, Etchegoyen GS, Guidi ML, Caporale JE, Martella A, Hera Mde L, Siri F, Bonelli P. PROPAT: a study to improve the quality and reduce the cost of diabetes care. Diabetes Res Clin Pract. 2006 Jun;72(3):284-91.

32. Gagliardino JJ, Lapertosa S, Pfirter G, Villagra M, Caporale JE, Gonzalez CD, Elgart J, González L, Cernadas C, Rucci E, Clark C Jr; Clinical, metabolic and psychological outcomes and treatment costs of a prospective randomized trial based on different educational strategies to improve diabetes care (PRODIACOR). Diabet Med. 30(9):1102-1, 2013.

33. Prestes M, Gayarre MA, Elgart JF, Gonzalez L, Rucci E, Gagliardino JJ. DIAPREM (DIAbetes Primary care, Registry, Education and Management). Multistrategic approach to improve quality of care of people with diabetes at the primary care level: Study design and baseline data. Prim Care Diabetes. 2017 Apr;11(2):193-200.

34. Gagliardino JJ, de la Hera M, Siri F y el Grupo de investigación de la red QUALIDIAB. Evaluación de la calidad de la asistencia al paciente diabético en América Latina. Rev Panam Salud Pública. 2001;10:309-17.

35. Gagliardino JJ, Costa Gil JE, Faingold MC, Litwak L, Fuente GV. Insulina y control de la diabetes en la Argentina. Medicina (Buenos Aires) 2013;73:520-8

36. Mortensen HB, Vølund A, Christophersen C. Glucosylation of human haemoglobin A. Dynamic variation in HbA1c described by a biokinetic model. Clin Chim Acta. 1984;136(1):75-81.
37. Manley S. Haemoglobin A1c-a marker for complications of type 2 diabetes: the experience from the UK Prospective Diabetes Study (UKPDS). Clin Chem Lab Med. 2003 Sept 41(9):1182-90.

38. Pop-Busui R, Braffett BH, Zinman B, Martin C, White NH, Herman WH, Genuth S, Gubitosi-Klug R; DCCT/EDIC Research Group. Cardiovascular Autonomic Neuropathy and Cardiovascular Outcomes in the Diabetes Control and Complications Trial/Epidemiology of Diabetes Interventions and Complications (DCCT/EDIC) Study. Diabetes Care 2017; 40(1):94-100.

39. Stratton IM, Adler Al, Neil HA, Matthews DR, Manley SE, Cull CA, Hadden D, Turner RC, Holman RR. Association of glycaemia with macrovascular and microvascular complications of type 2 diabetes (UKPDS 35): prospective observational study. BMJ 2000; 321(7258): 405-12.

40. Garg N, Moorthy N, Kapoor A, Tewari S, Kumar S, Sinha A, Shrivastava A, Goel PK: Hemoglobin A(1c) in nondiabetic patients: an independent predictor of coronary artery disease and its severity. Mayo Clin Proc. 2014;89:908-16.

41. Buysschaert M Medina JL, Buysschaert B, Bergman M. Definitions (and Current Controversies) of Diabetes and Prediabetes. Curr Diabetes Rev. 2016;12(1):8-13.

42. Idris I, Smith G, Dhatariya K, Kirkpatrick ES and John WG. The effect of anaemia and abnormalities of erythrocytes indices on $\mathrm{HbA1c}$ analysis: a systematic review. Diabetologia 2015;58:1409-21.

43. Weykamp C. HbA1c: a review of analytical and clinical aspects. Ann Lab Med. 2013;33(6):393-400.

44. Little RR. Glycated Hemoglobin Standardization-National Glycohemoglobin Standardization Program (NGSP) Perspective. Clin Chem Lab Med. 2003;41(9):1191-8.

45. Weykamp C, John WG, Mosca A et al. The IFCC reference measurement system for HbA1c: a 6-year progress report. Clin Chem. 2008;54: 240-8.

46. Consensus Committee (2007) Consensus statement on the worldwide standardization of the hemoglobin $\mathrm{A}_{1} \mathrm{C}$ measurement: the American Diabetes Association, European Association for the Study of Diabetes, International Federation of Clinical Chemistry and Laboratory Medicine, and the International Diabetes Federation. Diabetes Care 2007 Sep; 30(9):2399-400.

47. World Health Organization (2011) Use of glycated haemoglobin ( $\mathrm{HbA1C}$ ) in the diagnosis of diabetes mellitus (abbreviated report of a WHO consultation).

48. Inzucchi SE, Bergenstal RM, Buse JB et al. Management of hyperglycemia in type 2 diabetes: a patient-centered approach: position statement of the American Diabetes Association (ADA) and the European Association for the Study of Diabetes (EASD). Diabetes Care 2012; 35:1364-137.

49. Kaiser P, Spannagl M, van Campenhout C, Lenga Y. HbA1c: EQA in Germany, Belgium and the Netherlands using fresh whole blood samples with target values set with the IFCC reference system. Clin Chem Lab Med 2016 Nov 1;54:1769-75.

50. Weykamp C, John G, Gillery P, English E, Ji L, Lenters-Westra E, Little RR, Roglic G, Sacks DB, Takei I, IFCC Task force on implementation of HbA1c Standardization. Investigation of 2 Models to set and evaluate quality targets for HbA1c: biological variation and sigma-metrics. Clin Chem. 2015 May;61(5): 752-9.

51. Hanas R, John G. 2010 Consensus statement on the worldwide standardization of the hemoglobin $\mathrm{A}_{1} \mathrm{C}$ measurement. Diabetes Care 2010 Aug; 33(8):1903-4.

52. Little RR, Rohlfing $\mathrm{CL}$. The long and winding road to optimal HbA1C measurement. Clin Chim Acta. 2013 Mar 15;418:63-71.

53. NGSP [Internet]. Factors that interfere with HbA1c test results; [updated 12-29-2016]. Available from: http://www.ngsp.org/factors. asp 
54. Geistanger A, Arends S, Berding C, Hoshino T, Jeppsson JO, Little R, Siebelder C, Weykamp C; IFCC Working Group on Standardization of Hemoglobin. Statistical methods for monitoring the relationship between the IFCC reference measurement procedure for hemoglobin A1c and the designated comparison methods in the United States, Japan, and Sweden. Clin Chem. 2008 Aug;54(8):1379-85.

55. Weatherall DJ, Clegg JB. Inherited haemoglobin disorders: an increasing global health problem. Bull World Health Organ. 2001;79(8):704-12.

56. Whiting DR, Guariguata L, Weil C, Show J. IDF diabetes atlas: global estimates of the prevalence of diabetes for 2011 and 2030. Diabetes Res Clin Pract. 2011;94:311-21.

57. Lorenzo-Medina M, De-La-lglesia S, Ropero P, Nogueira-Salgueiro $P$ and Santana-Benitez J. Effects of Hemoglobin Variants on Hemoglobin A1c Values Measured Using a High-Performance Liquid Chromatography Method. J Diabetes Sci Technol. 2014; 8(6):1168-76.
58. Imdahl R, Roddiger R, Casis-Saenz ET. Multicenter Evaluation of a New High-Throughput HbA1c Testing Platform. Clin Lab. 2016 Dec 1;62(12):2405-12.

59. Reimundo P, Valbuena H, Bérgamo S, Comas I, Martínez-López R, Ferrer R, Beneítez D, Casis E. Evaluation of HbA1c turbidimetric immunoassay on the new high-throughput analyzer cobas $C 513$ against ion exchange HPLC method and assessment of HbF interference on HbA1c measurement. 68th AACC Annual Scientific Meeting \& Clinical Lab Expo, Philadelphia- Pennsylvania, 2016.

60. Little RR, Rohlfing CL, Sacks DB, National Glycohemoglobin Standardization Program (NGSP) Steering Committee. Status of hemoglobin A1c measurement and goals for improvement: from chaos to order for improving diabetes care. Clin Chem. 2011 Feb; 57(2):205-14. 